\title{
Assessment of Factors Affecting Institutional Delivery Service Utilization Among Mother Who Gave Birth in Last Two Years, Arbaminch Town, Gamo Gofa Zone, Snnpr, Ethiopia
}

\author{
Woiynshet Gebretsadik Kelebore, Aschalech Asefa, Asefa Tunje, Shitaye Shibiru, Simret Hassen, \\ Dinkalem Getahun, Mesfine Mamo
}

Department of Nursing, Arba Minch University, Arba Minch, Ethiopia

\section{Email address:}

Woiynshetg@gmail.com (W. G. Kelebore), shitayeshibiru@yahoo.com (S. Shibiru),dinku153@gmail.com (D. Getahun), mefirich2007@yahoo.com (M. Mamo), asefatunje@gmail.com (A. Tunje)

To cite this article:

Woiynshet Gebretsadik Kelebore, Aschalech Asefa, Asefa Tunje, Shitaye Shibiru, Simret Hassen, Dinkalem Getahun, Mesfine Mamo. Assessment of Factors Affecting Institutional Delivery Service Utilization Among Mother Who Gave Birth in Last Two Years, Arbaminch Town, Gamo Gofa Zone, Snnpr, Ethiopia. Science Journal of Public Health. Vol. 4, No. 6, 2016, pp. 458-462.

doi: $10.11648 /$ j.sjph.20160406.17

Received: August 8, 2016; Accepted: August 20, 2016; Published: October 20, 2016

\begin{abstract}
Reducing maternal morbidity and mortality is a global priority which is particularly relevant to developing countries like Ethiopia. One of the key strategies for reducing maternal morbidity and mortality is increasing institutional delivery service utilization of mothers under the care of skilled birth attendants. Thus, this study was aimed at assessing factors affecting delivery service utilization among women who give birth during the period of two years in Arba Minch town. Community based cross sectional study was used and the required sample was 178. Study participants were selected using systemic sampling method from list of women who had given birth in the last two years in Arba Minch town. Detailed explanation and interpretation was made by presenting the data in the form of frequency, percentage using tables, graphs and odd ratio with $95 \% \mathrm{CI}$ was calculated to see the association $\mathrm{b} / \mathrm{n}$ the dependent $\&$ independent variable. A total of 168 women who gave delivery in the last two year prior to this study survey, were interviewed making a response rate of $94 \%$ and the prevalence of delivery service utilization was found to be $73.2 \%$.NoneEducated women were $27 \%$ less likely utilize the delivery service then educated [OR, $0.73395 \% \mathrm{CI}=0.468-1.149$ ]. Women who know the benefit of giving birth at HF were $44 \%$ more likely to utilize delivery service than [OR, $2.44495 \%$ $\mathrm{CI}=1.728-3.458]$.the women who have Knowledge of complication of labour were $44 \%$ more likely to utilize delivery service than the women who have Knowledge of complication of labour [OR 1.444, 95\% CI=1.728-3.458]. In this study age, monthly income, distance of the HF and knowledge on complication were associated with delivery service utilization. The concerned government office needs to work on creation of awareness.
\end{abstract}

Keywords: Institutional Delivery, Service, Knowledge, Utilization

\section{Introduction}

Despite progress in some countries, the global number of deaths per year, estimated at 529,000 or one women's death every minute has not changed significantly since the ICPD, according to recent estimate by WHO, UNICEF and UNFPA; ninety-nine percent of these deaths occur in developing countries. Millions more women survive but disability related to pregnancy and child birth. Yet, most of these deaths could be avoided if preventive measures were taken and adequate care was made [2-4].While it is recognized that almost half of the newborn deaths can be prevented by scaling up evidence-based available interventions such as tetanus toxoid immunization to mothers; clean and skilled care at delivery; newborn resuscitation; exclusive breastfeeding; clean umbilical cord care; management of infections in newborns, many require facility based and outreach services [21]. 


\section{Method and Material}

\subsection{Study Area}

This study was conducted in Arbaminch town. Arbaminch town is one of the 22 reform town in Ethiopia which is found in SNNPR, Gamo Gofa zone. The town is located $505 \mathrm{~km}$ from the capital city Addis Abeba. Arba Minch town has four sub-cities and there were around 351 women who have given birth in the last two years and the study was conducted from August 16, 2013 to August 30, 2013.

\subsection{Source and Study Population}

All women who have given birth in the last two years in Arba Minch town were the source population. Sampled 1 women who have given birth from August 15, 2011 to August 15, 2013 in Arba Minch were study population.

\subsection{Sample Size Determination and Procedure}

The sample size was calculated using Single population proportion formula based on the following assumption:

Where: $\mathrm{n}=$ sample size

$\mathrm{z}=$ standard distribution value for $95 \mathrm{CI}, \mathrm{z}=1.96$

$1-p=$ prevalence of institutional delivery service utilization $=0.3$ (From Butajira 2012)

$\mathrm{D}=$ marginal error $=0.05(5 \%)$

$$
n=\frac{Z^{2} P(1-P)}{d^{2}}
$$

There for $\mathrm{n}=(1.96) 2 * 0.30(.70)$

$(0.05) 2$

$\mathrm{n}=323$

To minimizing sample size population correction formula was used

$\mathrm{nf}=\mathrm{n} / 1+\mathrm{n} / \mathrm{N}$ Where

$\mathrm{ni}=$ calculated sample size

$\mathrm{nf}=$ exact sample size

$\mathrm{N}=$ sample population

$323 /(1+323 / 351)=170$ we added $5 \%$ for non-response rate 8 , so the required sample size was 178

\subsection{Sampling Procedure}

Arbaminch town has four Sub-cities and eleven kebele. The study was done in all kebele and the calculated sample size (178) was used to recruit study subjects from all kebeles proportional to the their size. The minimum number of participants included in the study from each kebele was assigned proportionately based on data obtained from the respective statistics office. Then, systematic random sampling was used to select and approach study subjects who gave birth in the last two years during data collection time.

Table 1. Proportional allocation of sample in all different kebeles in, Arba Minch town, Gamo Gofa zone SNNPR 2014 E.C.

\begin{tabular}{|c|c|c|c|}
\hline S.no & Name of kebele & Number of women who deliverer in the last two years & Proportional allocation \\
\hline 1 & Ediget Ber & 52 & $52 / 351 * 100 \%=14.8 \%=178 * 14 \backslash 100=26$ \\
\hline 2 & Menahria & 23 & $23 / 351 * 100 \%=7 \% 178 * 7 / 100=12$ \\
\hline 3 & Kulfo & 49 & $\begin{array}{l}49 / 351 * 100 \%=14 \% \\
178 * 14 \backslash 100=25\end{array}$ \\
\hline 4 & Dilfana & 41 & $\begin{array}{l}41 / 351 * 100 \%=12 \% \\
178 * 12 \backslash 100=21\end{array}$ \\
\hline 5 & Gurba & 26 & $\begin{array}{l}26 / 351 * 100 \%=7 \% \\
178 * 7 / 100=13\end{array}$ \\
\hline 6 & Wuha Minch & 37 & $\begin{array}{l}37 / 351 * 100 \%=11 \% \\
178 * 11 \backslash 100=20\end{array}$ \\
\hline 7 & Mehal Ketema & 19 & $\begin{array}{l}19 / 351 * 100 \%=5 \% \\
178 * 5 \backslash 100=9\end{array}$ \\
\hline 8 & Limat & 28 & $28 / 351 * 100 \%=8 \%=178 * 8 \backslash 100=14$ \\
\hline 9 & Bere & 30 & $30 / 351 * 100 \%=9 \%=178 * 9 \backslash 100=16$ \\
\hline 10 & Chamo & 20 & $20 / 351 * 100 \%=6 \%=178 * 6 \backslash 100=11$ \\
\hline 11 & Doyisa & 26 & $\begin{array}{l}26 / 351 * 100 \%=7 \% \\
178 * 7 \backslash 100=12\end{array}$ \\
\hline
\end{tabular}

\subsection{Data Collection Tools, Procedure and Quality}

Data collection format was developed after review of different related literature: the format include the following check list

- Socio-demographic characteristics (sex, age, residence, marital status, occupational status, educational status)

- Knowledgerelated information

- Obstetric related information,

- health service related information and

- Culture related information
Training and orientation on how to collect the data was given for the data collectorspre-test was conducted and possible modification was done based on the finding and after on the actual data collection was carried out. The data was collectedusing Semi Structured interview administered questionnaire.

\subsection{Data Quality Management, Processing and Analysis}

To ensure the quality of data, data collectors were trained nurses recruited from ANC and delivery unit. On the days of data collection the principal investigators and supervisor supervised the data collection. The data collector and 
supervisor were trained on the objective of study. The questioners were checked for completeness and consistency by principal investigator before data entry. Completed questioner were

Coded by number and entered in to a commuter software EPI info version 3.5.1 statistical package and exported to SPSS version 20.Cross checking and data cleaning was done for accuracy and consistency by running frequency of each variable by principal investigator. Detailed explanation and interpretation was made by presenting the data in the form of frequency, percentage using tables, graphs and odd ratio with $95 \%$ CI was calculated to see the association $b / n$ the dependent $\&$ independent variable.

\subsection{Study Variables}

\subsubsection{Dependent Variable}

- Delivery service utilization

\subsubsection{Independent Variables"}

- Socio demographic factor- (age, marital status, occupation, income, education, access to radio and distance)

- Knowledge variable -( pregnancy and labour danger sign, knowledge about pregnancy risk, attitude on health facility)

- Obstetric variables, (parity and ANC)

\subsection{Operational Definitions}

- Uneducated - a woman who is unable to read and write

- Educated - a woman who is able to read and write

- Recent delivered women - women who had a deliver within the last two years during the period of data collection.

- Knowledge - Those woman who answered more than $50 \%$ of knowledge related questions have good knowledge and those women who scored less 50\%of knowledge related questions have poor knowledge

- Institutional delivery - is women who gave birth in the health facilities by skilled professional

\subsection{Ethical Consideration}

Ethical clearance was obtained from ethical review committee of Arba Minch University, College of medicine and Health Science, department of nursing. An official letter from the college was sent to all kebeles of Arba Minch town in order to get permission for data collection. Verbal consent was obtained from each respondent before data collection. Subjects were told the confidentiality of the information that they are going to give. Ethical way of approaching was followed by the interviewers in a manner of respect of the culture, religion, language and other dignity of the community, their right to refuse.

\section{Result}

In this community based correctional study A total of 168 women, who gave delivery in the last two year prior to this study were interviewed making a response rate of $94 \%$ and the prevalence of delivery service utilization $73.2 \%$.

\subsection{Socio Demographic Characteristics}

In this study, majority $154(91.5 \%)$ were married, regarding their occupational status 115 (68\%) were housewives; most of the study participants are urban by residence, 134 (79.8) are educated and 90 (53.8) earn monthly income of less than 200ETB.

\subsection{Predictors of Institutional Delivery Service Utilization}

Out of the 168 study subjects, 102 (60.7\%) did not know about risks during pregnancy. Among the 70(41.4\%) who mentioned at least one risk during pregnancy and 98 (58.6) of them did not know any danger sign of pregnancy .Regarding the benefit of giving birth at health facility155 (92.3\%) responded at least one benefit.

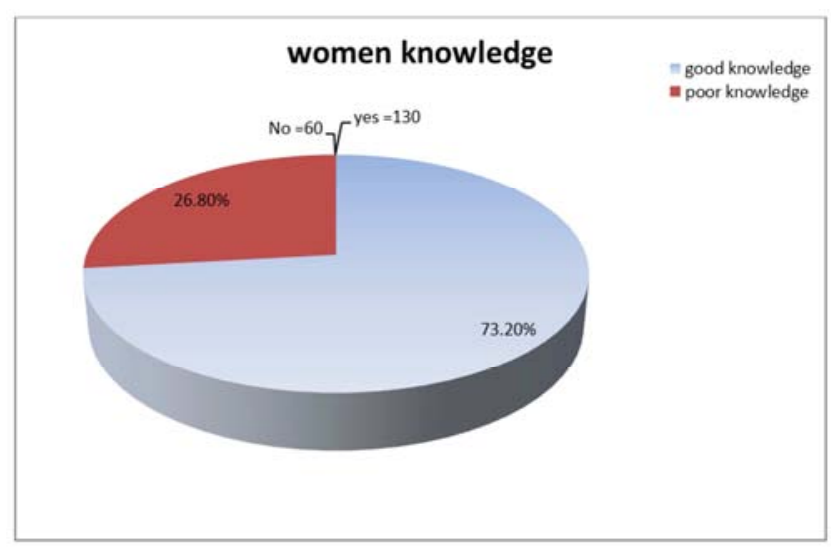

Fig. 1. Women's knowledge on utilization of delivery service in Arba Minch town Gamo Gofa zone SNNPR 2014 E.C.

Not Educated person were $73 \%$ less likely utilize the delivery service than educated (OR, $0.73395 \% \mathrm{CI}=0.468$ 1.149). Regarding Households who possess radio were $16 \%$ more likely to utilize delivery service than households who did not have radio [OR, 1.16895\% CI $=1.168-2.442$ ].

Households having monthly income200birrwere $73 \%$ more less likely utilize delivery service than those with monthly income200-400birr [OR 0.733 , 95\% CI $=0.468$ 1.149 ]. With regard to the health service factor distance ever used utilized the service. On the contrary, health facility at proximity, and ability to pay for the service were significantly associated with place of delivery [OR4.100, 95\% $\mathrm{CI}=2.751-6.111]$.

Women who have been living in areas more than ten min far away distance from health facility were less likely to utilize health service with [OR 1.156, 95\%CI=0.775-1.722 ]. Considering the maternal knowledge

e about knowledge on complication of labour, mothers who did not know knowledge on complication of labour were less likely to utilize delivery service than those mother who know at least one danger sign of pregnancy [OR 1.444, $95 \% \mathrm{CI}=0.988-2.112]$. Mothers who have not Planed pregnancy were less likely to utilize delivery service than 
those mother who had Planed pregnancy [OR 1.956, 95\% $\mathrm{CI}=1.365-2.801]$.

Table 2. Variables which have association with delivery service among women delivery in last two year in Arba Minch town Gamo Gofa zone 2014E.C.

\begin{tabular}{lllll}
\hline Variables & & Yes Number(\%) & No Number(\%) & OR 95\% CI \\
Age & $<18$ & 0 & 11 & $3.618(2.475-5.289)$ \\
& $>19$ & 123 & 45 & 1 \\
Radio avalablity & Yes & $76(45.2 \%)$ & $45(26.8 \%)$ & $1.168(1.168-2.442)$ \\
& No & $23(13.6 \%)$ & $27(16 \%)$ & 1 \\
Income & $<200$ & $33(19.6 \%)$ & $45(26.8 \%)$ & $0.733(0.476-1.149)$ \\
& $200-400$ & $45(26.8 \%)$ & $45(26.8 \%)$ & 1 \\
Planed pregnancy & yes & $88(52.4 \%)$ & $45(26.8 \%)$ & $1.956(1.356-2.801)$ \\
Way of service giving on & No & $17(10.1 \%)$ & $17(10.1 \%)$ & 1 \\
payment & $<=100-400$ & $3(1.7 \%)$ & $12(7.1 \%)$ & 1 \\
Knowlege on complication of & Yes & $123(73.2 \%)$ & $30(17.9 \%)$ & $1.400(2.751-6.111)$ \\
labour & No & $65(38.7 \%)$ & $45(26.8 \%)$ & 1 \\
Knowlege of benefit of giving & Yes & $29(17.2 \%)$ & $29(17.2 \%)$ & $2.444(1.728-3.485)$ \\
birth at HF & No & $110(65.4 \%)$ & $45(26.8 \%)$ & 1 \\
Able to pay delivery service & Yes & $7(4.1 \%)$ & $6(3.5 \%)$ & $4.100(2.751-6.111)$ \\
utilization & No & $33(73.4 \%)$ & $12(26.6 \%)$ & 1 \\
Knowlege & Poor Knowlege & $123(100 \%)$ & 0 & $0.422(0.247-0.722)$ \\
\hline
\end{tabular}

\section{Discussion}

This community -based study has tried to identify factors affecting delivery service utilization in Arba. Minch town .in this study, $73.2 \%$ of the mothers gave birth in the health facilities and it show the majority of the mother was delivered in health facility (26.8\%) preferred home delivery. This finding is almost consistent with the FMOH report (health and health related indictor) which is (23.7\%), SNNRP (16.7\%) and Sheka Zone $(25.1 \%)$. All of these studies showed that still high number of women was delivering at home being attended by untrained birth attendant and relatives.

From the total, $45(26.7 \%)$ of them were home deliveries. All of the home deliveries were attended by relatives and untrained TBA. This finding is consistent with Amhara Region EDHS 2011, 64.6 percent were attended by relatives but slightly lower than the finding in North Gondor (76.4\%) and $(72.6 \%)$ in Metekel Zone. This might be due to the trust on the family or the relatives in giving support and close attention. With regard to reasons for preferring home delivery, $(15.4 \%)$ had mentioned smooth and short duration of labor, $(7.7 \%)$ were preference to deliver in the presence of relatives, and $2.9 \%$ respectively. These findings have consistent with North Gondar study, (44.7\%) were due to short and smooth duration of labour, and accordingly, factors influencing delivery service utilization of women were identified. The factors were related to women and utilization of service. The study has identified several sociodemographic factors that have important influence delivery service utilization. In line with other studies socio demographic characteristics such as educational status of the respondent, income and having radio were the common predictors for delivery service utilization increased knowledge and access to delivery service.

The finding is consistent with the findings in North Gonder, Peru, Tanzania, and Bangladesh. Educated women are more likely to use institutional delivery than not educated mothers.
The possible explanation for why education is a key determinant could be that as a woman go up through the ladder of education, the more knowledgeable she will be about the use of health facility also education is likely to enhance female autonomy so that women develop greater confidence and capability to make decision about their own health. Mothers who reported access to radio were more utilize health facility delivery service than mothers who had not reported.

Mothers who had good knowledge were about more likely to utilize delivery service than mothers who had poor knowledge. This finding was consistent to the study done in Sikela District, Amhara Region, and in Tanzania also showed that the proportion of women with skilled care at delivery increased with knowledge of danger sign from 91 percent among women who did not mention any to 100 percent among who did mentioned four almost or more danger signs $(\mathrm{P}<0.005)$. Finally, this study recommended further research on quality of maternal health services; particularly delivery services the reason for gaps between the factor that affect delivery service utilization, providers and mothers' knowledge towards delivery service.

\section{Strength and Limitation of the Study}

Strength-Since we used trained data collector these decreased occurrence bias

Limitation - Since the study is retrospective there might be possibility of recall bias

\section{Conclusion}

This study identified that, Educational status, income, having radio, distance from health care center, knowledge of giving birth at health facility and knowledge on complication on labour of the women werean independent predictor of delivery service utilization.

The present study identified relatively good utilization 
delivery service in the study area during in the last two year of delivery. that is 73.2 percent of mothers delivered at health facilities while still majority had delivered at home.

\section{Recommendations}

Arba Minch town health office need to work on creation of awareness and Research and academic institutes need to do further research on the area.

\section{Acknowledgements}

First of all we would like to express our heart full thanks Arbaminch University, college of medicine and health science and department of nursing for giving this chance for doing this research report. We would like to acknowledge Arbaminch town health department and health center for their cooperation to give us available information. Finally we would like to express our heart full thanks to the study participants.

\section{References}

[1] Central statistic Authority Ethiopia: Demographic \& Health Survey, 2013.

[2] UNFPA. The Cairo consensus at 10 Population, reproductive health and the global efforts to end poverty. State of the World Population 2004.

[3] Ndie Elkenah Chubike and Idam Constance Demographic characteristics of women on theutilization of Maternal Health Services at Abakaliki Urban.

[4] WHO, "World Health Statistics 2013", World Health Organization, 2013.

[5] United Nations, "The Millennium Development Goals Report 2005", New York: United Nations, 2006.

[http://www.un.org/milleniumgoals/].

[6] WHO, "Skilled birth attendant", WorldHealth Organization, Nepal, 2006.

[7] http://www.nep.searo.who.int/LinkFiles/Home_Skilled_Birth_ Attendant1.pdf.

[8] Save the Children, "Surveying the First Day, State of the World's Mother 2013”, 2013.

[9] Central Statistical Agency [Ethiopia] and ORC Macro, "Ethiopia Demographic and Health Survey 2011", AddisAbaba, Ethiopia and Calverton, Maryland, USA: Central Statistical Agency and ORC Macro, 2011.

[10] The last ten kilometers project. Baseline house hold health survey, "Amhara, Oromia, SNNPR and Tigray", JSIResearch and training, Inc., Addis Ababa, Ethiopia, 2009.
[11] Shiferaw et al., "Why do women prefer home births in Ethiopia?", BMC Pregnancy and Childbirth, vol. 13, pp. 5,2013 .

[12] Teferra et al., "Institutional delivery service utilization and associated factors among mothers who gave birth in the last 12 months in Sekela District, North West of Ethiopia: A community - based cross sectional study" ,BMC Pregnancy and Childbirth, vol. 12, pp. 74, 2012.

[13] Ethiopia Federal Ministry of Health, "Report on the safe motherhood", Addis Ababa, Family Health Department, 2010.

[14] Ali Mehryar K, Wuleta B, Samuel Y, et.al., "Programmatic correlates of maternal healthcare seeking behaviors inEthiopia”, Ethiop. J. Health Dev, vol/issue: 24(1), pp. 92-99, 2010 .

[15] Tewodros A, Jemal H., Dereje H., "Utilization of antenatal care services among teenagers in Ethiopia", Ethiop. J.Health Dev, vol/issue: 24(3), pp. 221-225, 2010.

[16] Amano et al., "Institutional delivery service utilization in Munisa Woreda, South East Ethiopia: a community basedcross sectional study", BMC Pregnancy and Childbirth, vol. 12, pp. $105,2012$.

[17] Deepthi S., "Increasing institutional delivery and access to emergency obstetric care services in rural Uttar Pradesh", Journal of Family walfare, vol.56, 2010.

[18] Rose M, Japhet K, Melkzedeck, Leshabari et. al., "Use pattern of maternal health services and determinants of skilledcare during delivery in Southern Tanzania: implications for achievement of MDG-5 targets", BMC Pregnancy andChildbirth, vol. 7, pp. 29, 2007.

[19] Carol W, Moses M, Evans M, et al., "Delivery practices and associated factors among mothers seeking child welfare.

[20] Services in selected health facilities in Nyandarua south district, Kenya. Wanjira et al", BMC Public Health, vol. 11, pp. 360, 2011.

[21] Id 21 insight health. Improving the health of mothers and babies. August 2007.

[22] Family Health Department. Ministry of Health. Facility based rapid need assessment for the making pregnancy safer initiative: Implementation of four pilot regions in Ethiopia, March 2002.

[23] WHO, UNICEF, UNFPA and World Bank. Maternal mortality in 2007.Geneva, WHO, UNICEF and UNFPA; 2008.

[24] Herpassa, G and A. D. Dwivedi. Maternal Mortality in Ambo Hospital, A five year retrospective review: Ethiop J Reprod. Health, 2008; vol 2 No1.

[25] Factors affecting home delivery in rural Tanzania WHO 2007,

[26] Assessment of Factors for Safe Delivery Service Utilization North Shoaw Zone, Amhara Regional State, Ethiopia, 2009. 